\title{
Time as a Subject in Sustainable Consumption
}

\author{
Fatemeh Jouzi ${ }^{1, *} \mathbb{0}$, Katariina Koistinen ${ }^{2} \mathbb{D}$ and Lassi Linnanen ${ }^{1}$ \\ 1 Department of Sustainability Science, LUT University, 53850 Lappeenranta, Finland; Lassi.Linnanen@lut.fi \\ 2 Department of Management and Organisation, University of Turku, 20500 Turku, Finland; \\ Katariina.Koistinen@utu.fi \\ * Correspondence: fatemehjouzi@yahoo.com; Tel.: +358-449363764
}

Citation: Jouzi, F.; Koistinen, K.; Linnanen, L. Time as a Subject in Sustainable Consumption. Sustainability 2021, 13, 3331. https://doi.org/10.3390/su13063331

Academic Editor:

Francesco Caracciolo

Received: 13 January 2021

Accepted: 15 March 2021

Published: 17 March 2021

Publisher's Note: MDPI stays neutral with regard to jurisdictional claims in published maps and institutional affiliations.

Copyright: (c) 2021 by the authors. Licensee MDPI, Basel, Switzerland. This article is an open access article distributed under the terms and conditions of the Creative Commons Attribution (CC BY) license (https:/ / creativecommons.org/licenses/by/ $4.0 /)$.

\begin{abstract}
The aim of this paper was to assess the use and consistency of the time concept in the sustainable consumption context. In this field, time is generally defined as a limited resource, such as money, which is allocated to activities and understood by the activities that it is allocated to. We assessed time as a subject matter in the reviewed articles to verify how it was conceptualized and used in sustainable consumption. During this analysis, we defined six categories: time-use, time of use, time-related rebound effects, time-related value-action gap, time pressure, and time-related well-being. Despite identical definitions, there are some inconsistencies in the essential assumptions regarding time, and we observed that the current recognition of time in sustainable consumption debates is not comprehensive. Clarifying the difference between an objective definition of time and the practical knowledge that people have about time has applications in terms of developing sustainable consumption strategies and policies.
\end{abstract}

Keywords: time; sustainable consumption; everyday life; well-being; money; resource

\section{Introduction}

Time and its related terms are used in almost all branches of science. Going back to the definition of "sustainable development" from the World Commission on Environment and Development, "Sustainable development is development that meets the needs of the present without compro-mising the ability of future generations to meet their own needs" [1] (p. 54). The words "present," "future," and "generation" expose the importance of time and its linear and rhythmic features in sustainable development.

Time is a frequently used concept in terms of personal and social life routines. Accordingly, many scholars use this concept's self-explanatory meaning in their scientific debates, as is often also the case with energy or money, while literal interpretations of these useful conceptual scientific entities are very important in social studies, and people's welfare can be increased when definitions are more concerned with their practical knowledge of such essential concepts [2] (pp. 200-203).

In social contexts, time and practices are discussed regarding the fact that limited time is allocated to routines and everyday activities. In economics, as a science for studying human behavior concerning goals and the scarcity of resources [3] (p. 34), time is used and evaluated as a scarce means to be allocated to alternative practices. Time is one of many resources that individuals use in their daily lives [4] (p. 182), and this is the common definition that is used in sustainable consumption.

Although time has vastly been noted in sustainable consumption, so far there has not been a systematic review of time and its use in this context. This paper distinguishes and categorizes the conception and use of time in the reviewed articles in the sustainable consumption background. To achieve our goal, we scrutinized references to time and its aspects in literature, utilizing qualitative content analysis. Contribution is made to the research by classification of time concept and assessing the consistency and use of it in the reviewed articles. 
This paper has adopted three concepts to explore the notion of time. Namely, these concepts are "sustainable consumption," "time and consumption," and "time and wealth." The incorporation of these views is explained by the importance of time as a necessary resource with intrinsic value, in consumption as a repetitive practice, and in the move towards sustainable consumption. The paper is structured as follows: after addressing the three concepts, the methods of the paper are discussed. Then, the paper's findings are presented before the final discussion.

\subsection{Sustainable Consumption}

Contemporary consumption patterns in high-income societies of the developed world are not considered to be sustainable $[4,5]$. All efforts towards sustainable development necessitates sustaining the consumption patterns and levels [6,7]. In 1994, sustainable consumption was defined by the Oslo Symposium as "The use of services and related products which respond to basic needs and bring a better quality of life, while minimizing the use of natural resources and toxic materials as well as emissions of waste and pollutants over the life cycle of the service or product so as not to jeopardize the needs of future generations" [8]. However, regarding the interdisciplinary nature of the concept, there is no clear and unique definition for sustainable consumption $[9,10]$. During the last 25 years, the main concerns in this field have gradually evolved. Single-discipline practical approaches have given way to multi-disciplinary systemic approaches. The importance of consumer choice and consumption behavior has attracted attention, and consequently, the domain has expanded to various disciplines, including environmental science, business, and the social sciences [8]. Although sustainable consumption patterns are dependent on the economic, cultural, and political situation of the societies, the analysis of the consumption behavior is suggested as a key research topic in both developing and developed countries [7].

The weak and strong versions of sustainable consumption are recognized based on two notions of efficiency and sufficiency [6]. The first concept involves decreasing the resources required for the same amount of output, and the second one concerns reducing the output which requires behavioral changes [11]. The creation of new social norms and the establishment of new criteria for evaluating social practices are suggested as a path towards sustainable consumption [4] (p. 169).

In the proposed definition of sustainable consumption, time is directly mentioned in terms of "future generation", as it was emphasized earlier in the sustainable development definition. This is in line with the interpretation of Meadows et al. [12], in which time is a limitation. In addition, there are some more indirect connections between time and the definition of sustainable consumption regarding consumption patterns and wellbeing. The terms "use of services and products," "better quality of life," and "use of resources" are all issues in the strong version of the sustainable consumption. The sufficiency approach in its broad sense highlights changes in cultural values and concerns the quality of life [11] (p. 12).

Time is assumed to be an influencing factor in energy consumption regarding consumption patterns [13-15]. The Institute for Global Environmental Strategies (IGES) [16], in its recently published report focused on lifestyle carbon footprints and emphasized individuals' potential for sustaining personal and global consumption. Working hour reduction and its consequential rebound effects are other direct concerns of scholars [17-19]. Norms of the society affects consumption behavior [20], and the attitude-action gap has attracted attention in the recent studies [21]. Many of the topics in sustainable consumption are indirectly concerned with time. Consumption is a time-consuming activity with specific patterns and psychological aspects. Time as an effective factor in consumption activity appears in all the mentioned discussions. However, there is no proper understanding on time as a subject in sustainable consumption in the discipline. 


\subsection{Time and Consumption}

In general, people use their time as well as their money and other available resources. This is how a vast amount of literature illuminates the relationship between time and consumption. Jalas [22], in his study of the temporalities of consumption, discusses consumption as a time-consuming activity and suggests surveying individuals' consumption behaviors and their dependency on individuals' time-use patterns. He concludes that individuals consume not only to satisfy their needs but also for other reasons, which cannot simply be categorized under the unnecessary needs. He also claims that the identity of individuals is relevant to their consumption patterns as well as their autonomy. "Filling one's time" is another reason for consumption in modern societies. People are taught to fill their time through consumption; therefore, they intensify their consumption practices because they are afraid of experiencing empty time [20].

Shove et al. [23] gathered academic empirical research to aid in understanding the patterns of time-consuming activities in everyday life as well as in observing the connection between material culture and time consumption. To analyze the dependency of overconsumption and time pressures in the modern world, they draw on lifestyle routines. Everyday routines occur unconsciously, and during these habitual activities, our minds are usually focused on other things. In forming new routines such as new consumption behaviors or abandoning old routines, rhythms of everyday life must be surveyed.

\subsection{Time and Wealth}

In 1972, Meadows et al., in their report for The Club of Room's project, assessed The Limits to Growth. They noticed time in that report as a constraint. They assumed within one hundred years the plant would reach the growth limits. It took a while until scientific reports noticed time beyond its drawback role. The intrinsic value of time is the third criteria in our assessment. Noting the "wealth in time" in addition to the common idea of "wealth in goods" is an effective parameter in sustainable consumption [24]. The conventional grasp of time as wages per hour in dominant economic models of consumption is criticized, and the necessity for a qualitative understanding of the time factor in sustainable consumption is stressed. Extra time will not directly lead to a more sustainable lifestyle unless it is properly managed. People do not want "more free time" but "enough time for meaningful things" [24].

\section{Materials and Methods}

To accomplish the goal of distinguishing and categorizing the concept of time in the literature, qualitative content analysis was utilized since as it is a scientific method, it is conscious of the context. Qualitative content analysis is a scientific method that follows research standards for assigning categories to texts from alternative backgrounds via a defined step-by-step model [25] (p. 10). Regarding the lack of categorization of time in the literature, the alternative assessment methods, such as meta-analysis and bibliometric analysis, which are more based on statistics, were less convincing and not in line with the goal of this paper. We looked for scientific articles in the sustainable consumption field, which were concerned about time and its effects in discussion as a subject matter.

We limited our selection to articles published since 1994, when the first official definition of sustainable consumption was released [6]. The search was conducted in the Scopus database, and due to the language restrictions was limited to journal articles published in English. To narrow the results, regarding the goal of the study, the scattered articles in irrelevant subject areas were excluded.

The following combination was used:

(TITLE-ABS-KEY (sustainab* AND consumption) AND KEY (time OR temporal*)) AND PUBYEAR > 1993 AND PUBYEAR < 2020 AND (LIMIT-TO (LANGUAGE, "English"))

Sustainab* covers both sustainable and sustainability. Due to the importance of time as a subject matter in this study, the results were limited to the articles that had time or temporal* in the keywords. 
Applying these criteria on the 20 August 2019, 990 articles were found. After excluding irrelevant subject areas (engineering, computer science, mathematics, medicine, material science, biochemistry, chemistry, chemical engineering, nursery, physics and astronomy, immunology, neurology, pharmacy, and veterinary), 340 articles remained.

As time is a general term with various verbal use, many of the founded articles did not discuss the notion of time within the proposed frame. In the next step, the abstracts of the materials were reviewed, and 36 articles within which "time" was a subject matter were selected. Finally, and after assessing the primary selection of articles, 12 articles [13-15,17-20,26-30], which contained some debates and arguments on the roles and uses of the concept of time, were picked for content analysis.

Regarding the limitations in our method and material selection, we limited the analysis to articles published in scientific journals. The Scopus database might not reflect the social sciences as broadly as Google Scholar does. Additionally, the selection plan was partly subjective, and access to some of the articles was behind a paywall. However, our sample revealed gaps in the existing knowledge, and thus, the use of Google Scholar could provide a fruitful tool for upcoming studies.

Content analysis in this paper was a deductive content analysis. The goal of deductive content analysis is to systematically elicit the given category out of the selected documents [25] (p. 93). In this study, time categories and the terms which are relevant to them are extracted from the reviewed literature and are interpreted based on the designed content analytical procedure.

The process started by distinguishing the research question and the theoretical framework, which were modified during the research process until the final version was obtained. Analysis was developed regarding the strong version of sustainable consumption. Time and consumption are the other domains for the developed analysis. In the proposed area, time is a resource with intrinsic value and consumption is a resource-consuming activity. The research question is how time is conceptualized and used in sustainable consumption. The theoretical framework and connection of the concepts are summarized in Figure 1.



Figure 1. Theoretical framework.

The next step involved clarifying the desired categories and their relevant terms. All the time-related terms which in text were within the theoretical framework were distinguished in a dynamic process. These eventual distinguished terms and arguments lead to six categories. The first group of terms, namely the time-use, represented time as a limited resource which is allocated to consumption activities. Secondly, time was noted regarding the sequence of consumption. Time saving and its undesired consequences was the third concern in the reviewed literature. The pace of everyday life and its consequences as time pressure and the value-action gap in the decision making were classified separately to form the two next categories. A group of discussions, which were about the time-related well-being, were also divided as a category. The alternative terms used for describing the defined categories in the analyzed articles are shown in Table 1. 
Table 1. Categories and the used terms.

\begin{tabular}{|c|c|c|}
\hline Category & Statement & Terms Used \\
\hline Time-use & $\begin{array}{l}\text { Allocation of time to activities, activities } \\
\text { consuming time. }\end{array}$ & $\begin{array}{l}\text { time as a cost, time as a resource, time footprint, time } \\
\text { allocation, activity, state of doing }\end{array}$ \\
\hline Time of use & $\begin{array}{l}\text { Patterns and repetitions of activities in } \\
\text { everyday life. This category is about the } \\
\text { repetition and reproduction and } \\
\text { sequences of activities. }\end{array}$ & $\begin{array}{l}\text { time-use pattern, everyday life, demand side, rhythms, } \\
\text { sequences of practices, temporal performance, norms, } \\
\text { normality, habits, temporality, daily life, common } \\
\text { sense, behavioral structure }\end{array}$ \\
\hline Time-related rebound effects & $\begin{array}{l}\text { Accounts for non-intended results of } \\
\text { resource-saving. Time as a resource to be } \\
\text { saved can cause rebound effects. }\end{array}$ & $\begin{array}{l}\text { time rebound effect, timesaving, time efficiency, time } \\
\text { eco-efficiency, time investment, reduction in working } \\
\text { hours consequences }\end{array}$ \\
\hline $\begin{array}{l}\text { Time-related value-action } \\
\text { gap }\end{array}$ & $\begin{array}{l}\text { It is defined as the disparity between an } \\
\text { individual's environmental concerns and } \\
\text { their lifestyle. }\end{array}$ & $\begin{array}{l}\text { decision-making, dilemma, moral functions, living out, } \\
\text { schizophrenia paths }\end{array}$ \\
\hline Time pressure & $\begin{array}{l}\text { Time scarcity and the lack of time to } \\
\text { perform intended activities. }\end{array}$ & $\begin{array}{l}\text { time squeeze, hurriedness, slow movement, } \\
\text { accelerated lifestyle, stress, time-poor, time scarcity, } \\
\text { time shortage, waste of time, discretionary time }\end{array}$ \\
\hline Time-related well-being & $\begin{array}{l}\text { Beyond material aspects, time-related } \\
\text { aspects of well-being are a subject matter. }\end{array}$ & $\begin{array}{l}\text { subjective well-being, quality time, life satisfaction, } \\
\text { time preference, meaningful life, working time } \\
\text { reduction, eudaimonic and hedonic well-being, time } \\
\text { affluence, enjoyment, welfare, meaningful passage of } \\
\text { time, time sovereignty, paid work/leisure time }\end{array}$ \\
\hline
\end{tabular}

Coding rules were also determined and evolved during the process, and the extracted categories were classified to gain a suitable base for the final interpretations. For instance, to avoid numerous adverbs and terms relevant to time limitations, all psychological terms related to stress and intense emotions regarding time scarcity were classified in the "time pressure" category. In the material processing phase, time categories were coded and simultaneously, the rules and classifications were modified via a self-modified cycle. Finally, the extracted time-related notions and their cross appearances and inter-links were extracted and interpreted.

\section{Results}

In the reviewed literature, time is mostly noted for its allocation to consumption activities. In almost all the defined categories, debates are developed based on the use of time and time-consuming nature of the activities. Practice theories and the explanation that experiences of time are experiences of practices [23], describe the main theory for time debates in these articles. Some have discussed time-use as the main time related issue [14,19, $20,26,28]$, and some have involved this category in marginal arguments $[13,15,17,18,27,30]$. The time of use and patterns of activities also have appeared as the main topic $[13-15,19]$ as well as the marginal one [20,26-28]. The non-intended result of the time saving or the "time related rebound effect" was mainly discussed by Buhl et al. [17], Buhl and Acosta [18], and Jalas [19]. Smetschka et al. [14] have discussed this category as a marginal topic. The time-related value-action gap as the subject is discussed by Chai et al. [27]. However, some other authors also have provided marginal arguments on that $[15,20,29]$. Although time pressure has not been the main subject in any of the reviewed articles, the authors were concerned about its role in consumption [13,14,18,20,26-29]. Hansen [29] and Pullinger [30] were focused on time-related well-being. The significance of time from this point of view also appeared in other articles $[14,17-20,27,28]$. Frequency of categories in the analyzed articles is shown in Figure 2. 


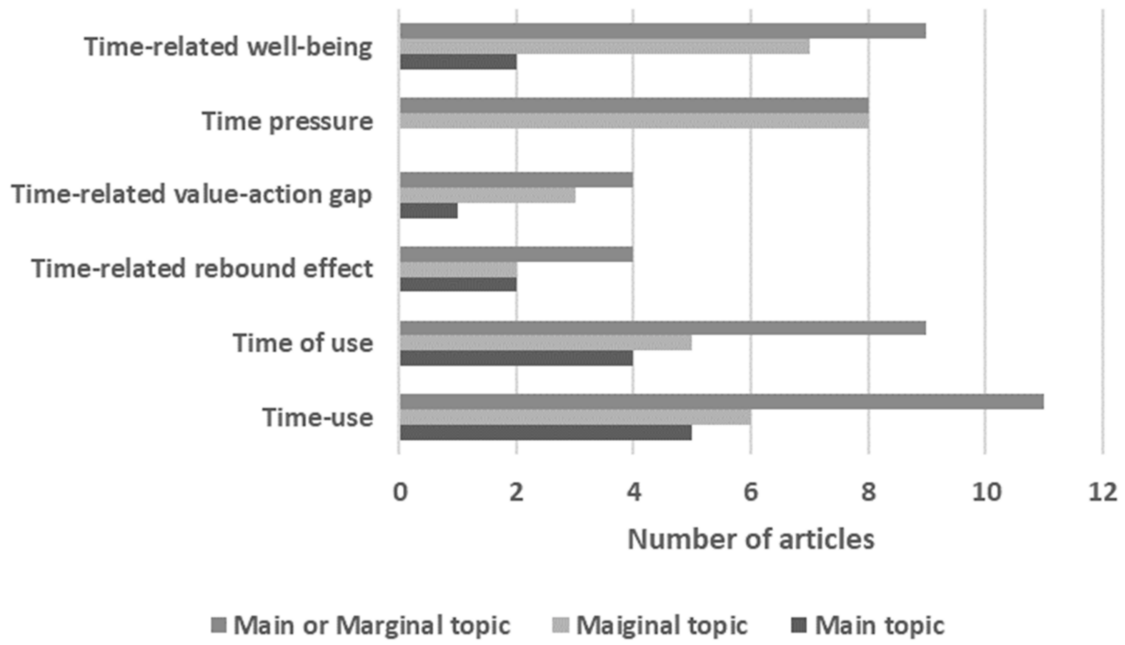

Figure 2. Presence of the categories in the analyzed articles.

Regarding the proposed framework, the use of time and its relevant discussions are presented in three sections. The time-consuming nature of activities is connected to the consumption pilar and discussions are mainly in the time-use category. The time-related rebound effect, time-related value-action gap, time pressure, and time related well-being are mostly about the value of time and are placed under the time pilar. Sufficiency related behaviors and patterns of activity which are discussed in the time-use category are covered by the third pilar under sustainable consumption.

\subsection{Time-Consuming Activities}

The carbon emissions of the activities is assigned to their allocated time and the time carbon footprint is discussed as criteria for assessing the sustainability of everyday activities. The carbon emissions of the activities assign to their allocated time so, sustainable consumption policies can be expanded from "consume less" to "spending time with low carbon activities". Hobbies with a high carbon footprint can be replaced by less carbon footprint ones. Consequently, carbon emissions during the time of leisure activities will decrease if the money that is not spent on hobbies is not spent on other carbon-emitting activities. Social engagement and volunteering activities are two of the low carbon-emitting leisure activities [14]. Definitely limiting the sustainability aspects of time to their emissions is causing the well-being-related impacts to be missed or underestimated. Aro [20] has focused on mobility as a time-consuming practice, which is directly connected to energy consumption. He has discussed its sustainability challenges in the Finnish context. Based on the practice theories, he used time to describe the complexity of mobility.

Moreover, consumption is analyzed as an activity with two components: time and commodity [28]. According to Arbuthnott and Scerbe [26] it is important to find the best combination of money or time cost and desired activities for getting the best result to mitigate environmental issues. However, it is not clear how time versus money is evaluated and what kind of relationship is assumed to exist between these two costs. Jalas [19] stresses that consumption can be limited by time but not necessarily by money. He has different preassumptions about the interchangeability of time and money compared to other authors.

\subsection{Time Value}

Time is a limited resource which is fairly shared among all humans [14]. Time is one of the necessary inputs in consumption activity and a lack of time leads to spending more money and making not-sustainable decisions [14]. For a sustainable performance, people spend more money or much time [26]. Regarding the limitation of time compared to the plentifulness of the materials, Cogoy [28] explains the necessity of the material-intensity of consumption and suggests that changing the balance of time and material in consump- 
tion activity leads to a decrease in the environmental consequences of the consumption. Time value is also seen in time-saving discussions. Saving resources potentially causes unintended consequences or a rebound effect [18]. In the same way time saving can cause rebound effect [17-19], time can be saved by using technologies and this saved time can be used for high-carbon emission activities. "Working time reduction" as a solution for reducing income and consequently consumption can cause reverse environmental results [17,18]. Liberated time does not necessarily lead to positive environmental impacts [18]. There must be services that provide "quality time" so that individuals would not exchange them for resource-intensive opportunities [17]. Buhl et al. [17] evaluated the time use rebound effect and income effect simultaneously for obtaining a reliable result. However, Jalas [19] presumes the non-interchangeability of time and money. He consciously avoids integrating income and time use rebound effects in his analysis. He stresses that individuals' reasons for attending activities are subjective and cannot be easily assessed by balancing available resources such as time, energy, and money.

Although income reduction negatively affects individuals, liberated time increases their happiness. Happiness studies show that the relationship between happiness and income or GDP decreases after a specific level of income [30]. According to Pullinger [30], there are three states of "having," "doing," and "being" in happiness. In the state of having, happiness will be limited to the basic physiological and psychological needs. In state of doing, time use, and activities are important. Spending time for meaningful activities increases happiness. State of being is more about values and perusing something other than needs and activities for a positive mental state. He stresses mindfulness and awareness are associated in this state of happiness and suggests for sustainable goals, happiness in state of doing and being get more attention compared to happiness in the state of having or monetary happiness.

\subsection{Sufficiency}

Time and its connection to consumption habits are discussed in the reviewed literature. Consumption routines are difficult to change $[15,27]$. Consumption patterns are hard to change because of the affluence, technologies and social norms and routines which cause a lock-in situation [27]. Everyday activities and personal rhythms are interconnected with institutions and infrastructures [15]. Gram-Hanssen et al. [13] consider the showering practice as a consumption case and survey shower timing and inter-related connection of its temporality with other rhythms and sequential practices during the day. Trying to answer the question "what time and how long?" they show that the temporality of the practices is dependent on the individual's social group. Practicing sustainable behaviors requires time and sustainable behavior is not adaptable with the usual professional life and pleasure leisure time [20].

Additionally, discretionary time is important in reducing the gap between accepted values and actions. Having no time to spend on time-consuming sustainable behaviors is considered a direct effect of time poverty [27]. Chai et al. [27] also suggest an indirect effect of time. The proposed indirect effect is the role of time affluence in the configuration of preference for acting sustainable behaviors. Subjective psychological characteristics are also important in the assessment of individual behaviors.

Correlation of well-being and developing sustainable habits is another topic of concern. Hansen [29] defines "subjective well-being" by two components, hedonic well-being which includes comfort, pleasure, and positive emotions, as well as eudaimonic well-being which includes personal flourishing, social relations, and generally meaning in life. Subjective well-being is not increasing by increased prosperity after some level. He argues that being concerned with environmental issues will increase individual's subjective well-being, since sustainable living gives some meaning to individual's life and results in more happiness and well-being. 


\subsection{Cross-Category Debates}

The analyzed literature revealed that the defined categories are interconnected, and their related debates have some inevitable overlaps. The possible debates regarding these connections are highlighted for a better clarification of time significance in sustainable consumption. Potentially, there could be 15 different cross-category debates, of which 14 debates are covered in the reviewed literature. The only debate that is not included in the analyzed articles is the correlation of time of use with time-related rebound effects. The most discussed relationships concern the connection of the time-related well-being category and the time-use category with other categories. Table 2 shows alternative correlations discussed by authors. A summary of category connections is presented in the following lines.

Table 2. This table shows the correlation of categories discussed by authors.




Activities repeat in an individual's everyday life, and any analysis of activities' carbon footprints under the time-use category can be better understood when the patterns of everyday life and the limitations in terms of changing these patterns are considered. Social norms which are categorized under the time of use affect individual activities and consumption [14]. For example, normality affects an individual's mobility activity and common mentality defines appropriate mobility [20]. Understanding the relationship between activities and their temporality is necessary for shaping a sustainable lifestyle. The disposition of actions throughout the day and the sequences of practices must be interpreted together [15]. The analysis of time-use leads to understating consumption habits and routines [28], which is significant for changing behaviors. Moreover, time consuming activities as well as the patterns of those activities are both affected by individuals' social groups [13].

Time allocation is also influenced by innovations and the consequent time efficiency [17] which is the subject in the time-related rebound effect.

Sustainable consumption activities are usually time-consuming, and this is potentially a reason for sustainable activities not being performed [27]. Allocating time to all individuals' needs causes a feeling of time pressure. Time squeezing can lead to high carbon-emitting activities [14]. In modern lifestyle, time scarcity is an issue, and time costs must be assessed and considered [26]. Time scarcity has been a reason for materialintensive consumption. With regards to the environmental issues, the proportion of time-use/commodity-use in daily life must change [28]. The final aim of activities is that of individuals' quality of life. This is the meeting point of time-use and well-being categories. Needs are subjective, and welfare is relative and culturally dependent. Goal-oriented consumption can be replaced by playful activities, which are more related to identities and can make the time duration more meaningful [19].

The level of income and social infrastructures shape consumption patterns [14]. In high-income societies, consumption patterns or time of use are hard to change because they are locked into social norms and habits [27]. Social norms and cultural values strongly affect the individual behavior and decisions about sustainability issues. Some people do not perform sustainable behaviors because neglecting such troubles makes them feel safer [29]. Additionally, rush hours and interconnected social rhythms are related to a feeling of time pressure [13]. Discretionary time can weaken a habit loop in favor of practicing more sustainable consumption behaviors and reduce the value-action gap [27].

Subjective well-being is potentially a motivation for changing routines in everyday life. Sustainable consumption is not just an ethical behavior. The eudaimonic aspect of well-being (positive feelings beyond pleasure) lead to the modification of everyday life [29]. Discretionary time reduces stress. When stress decreases, people are more likely to practice sustainable behaviors [27]. A lack of time affects individuals' decision-making in terms of a preference for less sustainable actions, for example, driving instead of walking [14]. Time squeezing limits individuals' consumption choices. In affluent societies, people do not have enough time to enjoy their prosperity. On the other hand, time squeezing affects the formation of preferences [27]. The reduction in time pressure because of working hour reduction increases life quality. In other words, more leisure time reduces time pressure [14] Increasing leisure time leads to a new balance between time and income as resources to be spent on activities. Potentially, life satisfaction increases by increasing leisure time because time can be allocated to individuals' preferences. As income decreases through saving time by reducing working hours, a smart balance of time-use increases well-being [18]. The substitution of household activities for market services for timesaving and welfare is associated with time-related rebound effects [19]. People are not theoretically "rational" in practice [17] and time-related rebound effects are consequences of their preferences [14].

\section{Discussion}

The findings imply that, in the sustainable consumption context, time as a resource is supposed to sustain other resources. Time as an objective concept is vastly used in 
the scientific literature; however, in sustainable consumption, some authors has involved subjective understanding of time in the time-related well-being category $[19,29]$ and in the time-use and time-related rebound effect categories [19].

Based on this analysis, an inconsistency in presumptions about time is emerging in the time-use category. Although many authors have considered commodities (including money) and time as two separate flows of inputs in terms of activities $[14,20,26,28]$, they all consider a balance between these two resources, which alters the assumption of Jalas [19]. Building on discussions about the same theory, using the same term-a time-use approachand regarding time as a resource, Jalas uses a different essential assumption about the non-interchangeability of time and money, and this assumption affects his methodology and results. The findings point to the fact that all authors refer to the practice theory and its definitions. Arguably, the research on time and sustainable consumption entails a dichotomy.

To this end, the findings imply that the current realization of time in sustainable consumption debates is not comprehensive enough. Any attempts to find a balance between time and monetary flows show the importance of a clear realization of the time-money or time-commodity relationship. Jalas stresses that individuals' reasons for performing activities are extremely subjective and not simple enough to be assessed by balancing available resources, such as time, energy, and money.

The intrinsic differences between time and money or other resources must be considered before treating them as interchangeable resources and comparing them with each other. Time and money are intrinsically different. For instance, money needs to be exchanged for something else to result in pleasure. By reducing time to an objective resource, quantitative measures are used for managing consumption and the carbon footprints of activities; however, there are some other aspects of time that are neglected. In time-related well-being category debates, the authors discussed how not only the "activity" is important for satisfaction but so is quality time and mindfulness. People lose some "quality time-related value" when they exchange their time for money, unless their working hours are quality time. Therefore, via reducing working hours, that hidden value of time will not be lost in exchange for money. Accordingly, regarding time pressure, people do not always suffer from a lack of time as an objective continuum of seconds, but rather they suffer from a lack of quality time. Moreover, time cannot be stored, unlike other resources such as money. When we define time in terms of activities, people are stimulated to fill all their available seconds with activities, and this is the cause of such pressure. The relationship between time and activities consists of aspects other than the relationship between a resource and what it is allocated to or spent for. Individuals' resources in terms of core economic resources, such as time [3] (p. 80), must be evaluated beyond their objective monetary value, and this must be the primary step taken towards the suggested solutions concerning the reduction in paid working hours.

Money or energy (to be spent or used) and time (to be allocated) are not balanced, and this results in an extra time pressure, which people feel in their daily lives. Unlimited access to money or energy threatens our limited time. We do not have enough time to spend the money that comes from unlimited growth. We do not have enough time to use the unlimited renewable energies that we have access to. Our daily time is limited as well as our monthly time. Designing a scale for measuring limits for the money to be spent daily or monthly and for the energy to be used daily or monthly is a topic for future research in this field.

Finally, as more people become aware of time's intrinsic value regarding pleasure, their consumption behavior will be more dematerialized. Creating value based on a customer's wish for spending quality time is already known by some businesses. Developing sustainable business models based on quality time is a suggested topic. Future studies should evaluate whether this approach can enable the transition towards more sustainable consumption patterns and stronger sufficiency-oriented policies. 
Time is a concept that is not limited to a specific domain of human knowledge. Regarding the goals and scope of this study, the debates are limited to scientific frameworks, and many humanity branches of knowledge, such as philosophy and art, are left out, despite there being many discussions within them on the topic throughout history. Even within science, linguistic debates and cognitive arguments are not included in our study. Thus, future research avenues could incorporate broader research openings from various disciplines.

"Consumption" is known to be a social activity with alternative purposes, rather than just simple economic goals. To this end, beyond needs and wants, there are some reasons for consumption to be investigated in future research. In addition, the recombination of resources such as money, time, and energy and the relocation of the well-being perspective on the map of consumption behaviors are deferred to future works.

Our analysis shows that time is used variously in the sustainable consumption context and the proposed categories make a framework which demonstrates the dimensions of the appearance of time in this field. Finally, the observed gaps and inconsistencies in the use of the time concept leads us to the need for more future studies.

Author Contributions: Writing—original draft preparation, F.J; review and editing, K.K.; supervision, L.L. All authors have read and agreed to the published version of the manuscript.

Funding: This research received no external funding.

Institutional Review Board Statement: Not applicable.

Informed Consent Statement: Not applicable.

Conflicts of Interest: The authors declare no conflict of interest.

\section{References}

1. Report of the World Commission on Environment and Development-Our Common Future; United Nation General Assembly Official Document A/42/427. 1987. Available online: http://sustainabledevelopment.un.org/milestones/wced (accessed on 16 March 2021).

2. Labanca, N. Complex Systems and Social Practices in Energy Transitions: Framing Energy Sustainability in the Time of Renewables, 1st ed.; Labanca, N., Ed.; Green Energy and Technology; Springer International Publishing: Cham, Switzerland, 2017; ISBN 978-3-319-33753-1.

3. Raworth, K. Doughnut Economics: Seven Ways to Think like a 21st-Century Economist; Random House Business Books: London, UK, 2017; ISBN 978-1-84794-139-8.

4. Gough, I. Heat, Greed and Human Need: Climate Change, Capitalism and Sustainable Wellbeing; Edward Elgar Publishing: Cheltenham, UK, 2017; ISBN 978-1-78536-510-2.

5. Druckman, A.; Jackson, T. The Bare Necessities: How Much Household Carbon Do We Really Need? Ecol. Econ. 2010, 69, 1794-1804. [CrossRef]

6. Fuchs, D.A.; Lorek, S. Sustainable Consumption Governance: A History of Promises and Failures. J. Consum. Policy 2005, 28, 261-288. [CrossRef]

7. Wang, C.; Ghadimi, P.; Lim, M.K.; Tseng, M.-L. A Literature Review of Sustainable Consumption and Production: A Comparative Analysis in Developed and Developing Economies. J. Clean. Prod. 2019, 206, 741-754. [CrossRef]

8. Liu, Y.; Qu, Y.; Lei, Z.; Jia, H. Understanding the Evolution of Sustainable Consumption Research: A Bibliometric and Network Analysis (1995-2014). Sust. Dev. 2017, 25, 414-430. [CrossRef]

9. Geels, F.W.; McMeekin, A.; Mylan, J.; Southerton, D. A Critical Appraisal of Sustainable Consumption and Production Research: The Reformist, Revolutionary and Reconfiguration Positions. Glob. Environ. Chang. 2015, 34, 1-12. [CrossRef]

10. Piligrimienè, Ž.; Žukauskaitè, A.; Korzilius, H.; Banytè, J.; Dovalienè, A. Internal and External Determinants of Consumer Engagement in Sustainable Consumption. Sustainability 2020, 12, 1349. [CrossRef]

11. Linnanen, L.; Nyfors, T.; Heinonen, T.; Liimatainen, H.; Nissinen, A.; Regina, K.; Saarinen, M.; Seppälä, J.; Viri, R. The Sufficiency Perspective in Climate Policy: How to Recompose Consumption, 4th ed.; Finnish Climate Change Panel: Helsinki, Finland, 2020; Volume 10.

12. Meadows, D.H.; Club of Rome (Eds.) The Limits to Growth: A Report for the Club of Rome's Project on the Predicament of Mankind; Universe Books: New York, NY, USA, 1972; ISBN 978-0-87663-165-2.

13. Gram-Hanssen, K.; Christensen, T.H.; Madsen, L.V.; do Carmo, C. Sequence of Practices in Personal and Societal RhythmsShowering as a Case. Time Soc. 2020, 29, 256-281. [CrossRef]

14. Smetschka, B.; Wiedenhofer, D.; Egger, C.; Haselsteiner, E.; Moran, D.; Gaube, V. Time Matters: The Carbon Footprint of Everyday Activities in Austria. Ecol. Econ. 2019, 164, 106357. [CrossRef] [PubMed] 
15. Southerton, D. Habits, Routines and Temporalities of Consumption: From Individual Behaviours to the Reproduction of Everyday Practices. Time Soc. 2013, 22, 335-355. [CrossRef]

16. Institute for Global Environmental Strategies; Aalto University; D-mat Ltd. 1.5-Degree Lifestyles: Targets and Options for Reducing Lifestyle Carbon Footprints; Institute for Global Environmental Strategies: Hayama, Japan, 2019; ISBN 978-4-88788-220-1.

17. Buhl, J.; von Geibler, J.; Echternacht, L.; Linder, M. Rebound Effects in Living Labs: Opportunities for Monitoring and Mitigating Re-Spending and Time Use Effects in User Integrated Innovation Design. J. Clean. Prod. 2017, 151, 592-602. [CrossRef]

18. Buhl, J.; Acosta, J. Work Less, Do Less? Working Time Reductions and Rebound Effects. Sustain. Sci. 2016, 11, 261-276. [CrossRef]

19. Jalas, M. A Time Use Perspective on the Materials Intensity of Consumption. Ecol. Econ. 2002, 41, 109-123. [CrossRef]

20. Aro, R. Normality against Sustainability-Mobility Practices of Well-to-Do Households: Normality against Sustainability. Environ. Pol. Gov. 2016, 26, 116-128. [CrossRef]

21. Park, H.J.; Lin, L.M. Exploring Attitude-Behavior Gap in Sustainable Consumption: Comparison of Recycled and Upcycled Fashion Products. J. Bus. Res. 2020, 117, 623-628. [CrossRef]

22. Jalas, M. Busy, Wise and Idle Time: A Study of the Temporalities of Consumption in the Environmental Debate; Acta Universitatis Oeconomicae Helsingiensis A; Helsinki School of Economics: Helsinki, Finland, 2006; ISBN 978-952-488-036-7.

23. Shove, E.; Trentmann, F.; Wilk, R.R. (Eds.) Time, Consumption and Everyday Life: Practice, Materiality and Culture; Cultures of Consumption Series; Berg: Oxford, UK; New York, NY, USA, 2009; ISBN 978-1-84788-364-3.

24. Reisch, L.A. Time and Wealth. Time Soc. 2001, 10, 367-385. [CrossRef]

25. Mayring, P. Qualitative Content Analysis: Theoretical Foundation, Basic Procedures and Software Solution; Social Science Open Access Repository: Klagenfurt, Austria, 2014. Available online: https://www.ssoar.info/ssoar/handle/document/39517 (accessed on 16 March 2021).

26. Arbuthnott, K.; Scerbe, A. How Do Money and Time Restrictions Influence Self-Constraining Behavior in Polluting the Commons? Organ. Environ. 2017, 30, 211-225. [CrossRef]

27. Chai, A.; Bradley, G.; Lo, A.; Reser, J. What Time to Adapt? The Role of Discretionary Time in Sustaining the Climate Change Value-action Gap. Ecol. Econ. 2015, 116, 95-107. [CrossRef]

28. Cogoy, M. Consumption, Time and the Environment. Rev. Econ. Househ. 2010, 8, 459-477. [CrossRef]

29. Hansen, K.B. Exploring Compatibility Between "Subjective Well-Being" and "Sustainable Living" in Scandinavia. Soc. Indic. Res. 2015, 122, 175-187. [CrossRef]

30. Pullinger, M. Working Time Reduction Policy in a Sustainable Economy: Criteria and Options for Its Design. Ecol. Econ. 2014, 103, 11-19. [CrossRef] 